ESTUDO COMPARATIVO ENTRE FERTILIZANTES FORNECEDORES DE ENXOFRE ( ${ }^{1}$ ). EDMIR SOARES e TOSHIO IgUE $\left({ }^{2}\right)$. Vários autores têm procurado demonstrar a importância do enxofre na agricultura $(3,4,5)$. Outros, baseados em estudos próprios, sugerem que, aliada à adubação normal com $\mathrm{N}, \mathrm{P}$ e $\mathrm{K}$, se faça também a aplicação de enxofre em doses convenientes, principalmente quando a adubação foi baseada em fertilizantes que não sejam à base de sulfatos $(6,7,8)$.

Com o objetivo de estudar comparativamente diversas formas de enxofre foi conduzido o experimento aqui relatado.

Material e métodos: O ensaio foi realizado em casa de vegetação sendo utilizados vasos de barro vitrificados internamente, com capacidade para $8 \mathrm{~kg}$ de solo. Foram estudados dois tipos de solos: latossolo vermelho-escuro, orto, coletado no município de Itapetininga, e latossolo vermelho-escuro, orto, coletado na Estação Experimental de Capão Bonito, os quais foram peneirados, muito bem homogenizados e retiradas amostras para análises química e granulométrica, as quais revelaram os resultados apresentados a seguir.

\title{
ANALISE QUTMICA:
}

\section{Itapetininga}

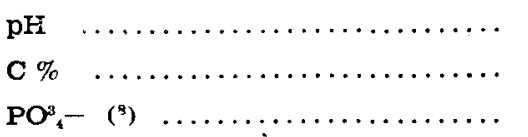

$\mathbf{K}+{ }^{(8)} \ldots \ldots \ldots \ldots \ldots \ldots \ldots \ldots$

$\mathrm{Ca}^{2}++\mathrm{Mg}^{2+}{ }^{(\mathrm{e})} \ldots \ldots \ldots \ldots \ldots \ldots$

$\left.\mathrm{Al}^{3}+{ }^{8}\right) \quad \ldots \ldots \ldots \ldots \ldots \ldots \ldots \ldots$

$\mathbf{S} . \mathbf{S O}^{2}{ }^{-}{ }^{\left({ }^{9}\right)} \ldots \ldots \ldots \ldots \ldots \ldots \ldots$

$\begin{array}{ll}5,38 & 5,23 \\ 3,70 & 2,30 \\ 0,01 & 0,01 \\ 0,12 & 0,13 \\ 0,71 & 0,23 \\ 0,70 & 1,40 \\ 3,20 & 6,40\end{array}$

\section{Capão Bonito}

5,23

2,30

0,01

0,13

0,23

1,40

6,40

(1) Recebida para publicação em 26 de julho de 1974

(2) Com bolsas de suplımentação do C.N.Pq.

(3) GOEPNERT, C. F. \& KUSSOW, W. R. Influência da calagem, enxofre e elementos menores na produção de matéria seca de soja e milho. In: Congr. bras. Ciência do Solo, XI, Brasília, 1967. Anais. Rio de J., Soc. bras. Ciência do Solo, 1971. p. 53.

(4) McClUNG, A. C.; FREITAS; L. M. M., GALLO, J. R. \& outros. Alguns estudos preliminares sobre possiveis problemas de fertilidade em solos de diferentes campos cerrados de São Paulo e Goiás. Bragantia 17:29-44, 1958.

(5) - MIKKELSEN, D. S. \& LOTT, W. L. A adubaçāo do algodoeiro em solos de campo cerrado no Estado de São Paulo. New York, IBEC Res. Inst, 1961. 35p. (Bol. 27)

(a) FREITAS, L. M. M.; TANAKA, T.; LOBATO, E. \& outros. Experimentos de adubação de milho-doce e soja em solos de campo cerrado. In: Simpósio sobre Cerrado, 1., São Paulo, 1961. São Paulo, Edit. Univ. S. Paulo, 1963. p. 323-358.

(7) doce e soja em solos de campo cerrado. In: Congr. bras Ciência do Solo, 11., Brasília, 1967. Anais. Rio de J., Soc. bras. Ciência do Solo, 1971. p. 39.

(8) e.mg/100 $\mathrm{ml}$ de solo.

(๑) ppm de $\mathrm{S} . \mathrm{SO}^{2}$, solúvel em sol. normal de acetato de amônia. 
ANALISE GRANULOMETRICA:

Itapetininga

65,0

3,7

29,2

2,1

Areia grossa

Classificação

Argila $\%$

Limo \%

Areia fina $\%$

O delineamento adotado foi o inteiramente casualizado, com três repetições dos tratamentos constantes do quadro 1, e que foram idênticos para cada solo em estudo.

Os níveis de $\mathrm{N}, \mathrm{P}_{2} \mathrm{O}_{5}$ e $\mathrm{K}_{2} \mathrm{O}$ foram, respectivamente, de $2,0-3,0-1,6 \mathrm{~g}$ por vaso, nas formas de salitre-do-chile, superfosfato triplo e cloreto de potássio.

Os níveis de enxofre foram 0,5 e $1,0 \mathrm{~g} /$ vaso e administrados através do emprego dos seguintes fertilizantes: sulfato de amônio, com $24 \%$ de enxofre; superfosfato simples, com $12 \%$ de enxofre; gesso, com $20 \%$, e flor-de-enxofre, com $99,85 \%$ de enxofre.

Evitaram-se os efeitos do nitrogênio e fósforo, fazendo um balanceamento dos mesmos em todos os tratamentos, de modo que as quantidades de $\mathrm{N}$ e $\mathrm{P}_{2} \mathrm{O}_{5}$ fossem iguais em todos eles.

A calagem foi realizada nos tratamentos correspondentes, em função do teor de $\mathrm{Al}^{3+}$ multiplicado pelo fator 1,5 , usando como material corretivo o calcário dolomítico proveniente da fábrica Apocal, situada no município de Saltinho, SP, e cuja análise foi a seguinte :

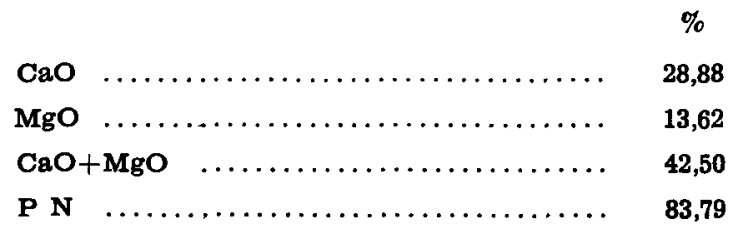

Como planta-teste, para avaliar a eficiência dos fertilizantes, cultivou-se trigo IRN 526-63, variedade comercial para o Estado de São Paulo, originada da CIMMYT-México. Foram plantadas doze sementes por vaso, deixando-se sete plantas após o desbaste.

Durante o transcorrer do experimento a irrigação dos vasos foj realizada com água desmineralizada.

Como controle de pragas, foram feitas pulverizações semanais com Dimecron $(50,1 \mathrm{cc} /$ litro $)$ e Karathane $(0,5 \mathrm{~g} / 1)$; ambos os 
produtos são isentos de enxofre. No final do ciclo as plantas foram cortadas bem rente ao solo, separadas as espigas das hastes, pesadas, e secas em estufa a $50-60^{\circ} \mathrm{C}$ até peso constante.

Resultados e discussão: As produções de matéria seca e de espigas de trigo obtidas no experimento encontram-se no quadro 1.

A análise estatística geral dos dados obtidos apresentou coeficientes de variação do experimento muito bons, sendo seus valores

QUADRO 1. - Produçōes médias de matéria seca e de espigas de trigo, obtidas em casa de vegetação em solos procedentes de duas localidades do Estado de São Paulo, em estudo comparativo entre fertilizantes fornecedores de enxofre

\begin{tabular}{|c|c|c|c|c|}
\hline \multirow{3}{*}{ TRATAMENTO (*) } & \multicolumn{4}{|c|}{ LATOSSOLO VERMELHO-ESCURO, ORTO } \\
\hline & \multicolumn{2}{|c|}{ Itapetininga } & \multicolumn{2}{|c|}{ Capão Bonito } \\
\hline & $\begin{array}{c}\text { Matéria } \\
\text { seca }\end{array}$ & Espiga & $\begin{array}{c}\text { Matéria } \\
\text { seca }\end{array}$ & Espiga \\
\hline & $\mathbf{g}$ & $\mathbf{g}$ & $\mathbf{g}$ & $\mathbf{g}$ \\
\hline NPKS & 16,3 & 9,7 & 12,5 & 6,8 \\
\hline NPKS $_{1}$ como S.A. $\quad \ldots \ldots \ldots \ldots$ & 30,7 & 22,7 & 27,7 & 21,7 \\
\hline NPKS $_{2}$ como S.A. $\ldots \ldots \ldots \ldots$ & 32,5 & 24,0 & 29,5 & 23,5 \\
\hline NPKS $_{1}$ como s.S. $\ldots \ldots \ldots \ldots$ & 32,0 & 23,8 & 30,0 & 25,0 \\
\hline NPKS $_{2}$ como S.S. $\ldots \ldots \ldots \ldots$ & 36,0 & 26,8 & 29,2 & 21,8 \\
\hline NPKS $_{1}$ como G. $\ldots \ldots \ldots \ldots$ & 31,5 & 25,0 & 27,6 & 22,8 \\
\hline NPKS $_{2}$ como G. $\ldots \ldots \ldots \ldots$ & 31,3 & 28,0 & 29,8 & 23,8 \\
\hline NPKS $_{1}$ como F.E. $\ldots \ldots \ldots \ldots$ & 31,8 & 24,8 & 37,7 & 21,7 \\
\hline NPKS $_{2}$ como F.E. $\ldots \ldots \ldots \ldots$ & 30,7 & 23,2 & 27,5 & 21,3 \\
\hline NPK + calagem $\ldots \ldots \ldots \ldots$ & 28,2 & 14,8 & 17,8 & 13,3 \\
\hline NPKS $_{1}+$ Cal. como S.A. $\ldots$ & 42,8 & 34,8 & 44,7 & 39,3 \\
\hline NPKS $_{2}+$ Cal. como S.A. $\ldots$ & 43,7 & 36,7 & 44,7 & 41,3 \\
\hline NPKS $_{1}+$ Cal. como S.S. . . & 46,0 & 37,5 & 43,7 & 40,5 \\
\hline $\mathrm{NPKS}_{2}+$ Cal. como S.S. $\ldots$ & 47,7 & 41,0 & 46,3 & 41,3 \\
\hline $\mathrm{NPKS}_{1}+$ Cal. como G. $\ldots$. & 45,2 & 38,7 & 42,7 & 38,5 \\
\hline NPKS $_{2}+$ Cal. como G. $\ldots$. & 47,8 & 35,8 & 44,2 & 39,7 \\
\hline NPKS $_{1}+$ Cal. como F.E. $\ldots$ & 43,2 & 35,5 & 41,3 & 38,0 \\
\hline NPKS $_{2}+$ Cal. como F.E. $\ldots$ & 42,2 & 34,2 & 39,0 & 34,8 \\
\hline C.V. \% (geral) & 7,2 & 6,4 & 4,4 & 4,9 \\
\hline
\end{tabular}

(*) S.A. - sulfato de amônio

S.A. - superfosfato simples

F.E. - flor-de-enxofre

G. - gesso

Cal. - calagem 
iguais a $7,2 \%, 6,4 \%$ e $4,4 \%, 4,9 \%$, respectivamente para os dados obtidos em massa seca e espiga nos solos de Itapetininga e de Capão Bonito.

A análise da variância para os dados de produção de massa seca de trigo no solo de Itapetininga indicou significância no teste F. para o efeito de formas de enxofre e para níveis de calcário, o mesmo não ocorrendo quanto aos níveis de enxofre nem para as interações. A estatística nos permite estudar o efeito médio das formas de enxofre, dentro dos níveis do elemento e observa-se que para os dados de produção de massa seca, somente o superfosfato simples apresentou-se superior ao fertilizante flor de enxofre, sendo os demais estatisticamente semelhantes entre si. Não foi observado efeito de níveis de enxofre aplicado. O teste Tukey a $5 \%$, revelou uma diferença mínima significativa igual a 2,92. Relativamente à produção de espigas obtidas no solo de Itapetininga, a análise da variância ( $F$ ) apresentou significância para as formas de enxofre, para níveis de calcário e para interação formas de enxofre com níveis de enxofre, não ocorrendo significância para os demais casos $O$ teste de Tukey a $5 \%$, apresentou um valor para a diferença mínima significativa igual 2,02. Pode-se observar que o efeito médio das formas de enxofre dentro de cada nível do elemento indica 0 gesso como o fertilizante que melhor se apresentou com o nível 1 de enxofre, juntamente com o superfosfato simples e a flor-de-en. xofre, sendo o sulfato de amônio o que menor produção apresentou. Dentro do nível 2 de enxofre, aparecem ainda o gesso e o superfosfato simples se sobressaindo dos demais, mas desta feita sendo a forma de enxofre elementar a menos efetiva, chegando mesmo a ter sua produção reduzida em relação ao nível 1 .

Quanto ao efeito médio dos níveis de enxofre dentro das formas de enxofre, observamos que somente para o superfosfato simples houve significância entre os níveis 1 e 2 de enxofre; para as demais formas não houve significância.

A análise da variância da produção de massa seca obtida com o solo coletado em Capão Bonito apresentou significância para o teste $F$ somente para formas de enxofre e níveis de calcário, não havendo significância para os demais casos, a exemplo do ocorrido com o solo de Itapetininga, para a produção de massa seca. 2,30 .

$O$ teste de Tukey a $5 \%$, neste caso apresentou d.m.s. igual a

Dentro do nível zero de calagem a análise demonstrou que não houve significância entre as formas de enxofre, o que é de se estranhar pois se há significância entre os níveis de calcário, acreditamos que neste caso o gesso deveria apresentar respostas mais intensas, devido ao mesmo apresentar uma boa percentagem de 
cálcio em sua composição. Mas dentro do nível 1 de calcário, somente o fertilizante flor-de-enxofre foi inferior estatisticamente aos três outros em estudo.

0 efeito médio das fontes dentro dos níveis de enxofre demonstrou, também aqui, que somente o fertilizante flor-de-enxofre foi estatisticamente inferior aos demais.

Por último, a análise da variância da produção de espigas de trigo obtidas no solo de Capão Bonito apresentou significância para os itens forma de enxofre, níveis de calcário e para a interação entre formas e níveis de enxofre. 0 teste de Tukey a $5 \%$ neste caso apresentou o valor d.m.s. igual a 2,19. O efeito dos fertilizantes, dentro de cada nível de enxofre, apresentou para 0 nível 1 a igualdade estatística entre sulfato de amônio e superfosfato simples e o gesso, sendo os dois primeiros superiores ao fertilizante flor-de-enxofre. No nível dois de enxofre, o fertilizante flor-de-enxofre tornou a ser estatisticamente inferior aos demais, que se igualaram entre si. Por outro lado, o efeito dos níveis de enxofre apresentou significância apenas para o sulfato de amônio e flor-de-enxofre, não apresentando diferença para o superfosfato simples e o gesso.

Considerações gerais: $\mathrm{O}$ interesse maior deste trabalho é o de ter-se estudado comparativamente o sulfato de cálcio (gesso) e o enxofre elementar como fontes de enxofre, pois, com o aumento de insumos concentrados em nitrogênio e fósforo, onde o enxofre não aparece nas suas composições, levará nossos solos até à deficiência de enxofre se não o adicionarmos como complemento à adubação normal.

Como no experimento se aplicou o enxofre nas formas de sulfato solúvel, sulfato pouco solúvel e enxofre elementar, lógico seria esperar que as melhores respostas seriam em ordem decrescente das mais solúveis para as menos solúveis, principalmente em se tratando de experimento em vasos, onde não há perdas por lavagem, pois o percolado é retornado ao vaso. Mas, como se pode observar na apresentação dos dados obtidos, o gesso que tem forma de enxofre pouco solúvel, no geral foi o que melhor se apresentou, principalmente quando o comparamos com enxofre na forma elementar.

Os resultados contrariam os obtidos por Juste e outros $\left({ }^{10}\right)$ que. estudando comparativamente enxofre elementar, sulfato de potássio, sulfato de cálcio e superfosfato em solos deficientes em enxofre, não observaram diferenças significativas entre várias fontes de fertilizantes utilizadas, apesar do aumento de produção da alfafa ter sido de 70 a $77 \%$ com a adição de enxofre.

(10) JUSTE, C. J.; TAUZIN, J. \& MENET, M. Carence en soufre de la luzerne en sol de charente. II - Efficacité comparée de diverses sources de soufre. C. r. hebd. Séance Agric. Fr. 55:420-424, 1968 . 
Desta maneira, como observações preliminares, acreditamos que o objetivo procurado foi alcançado, restando agora, com base nos mesmos, comprovar a eficiência do sulfato de cálcio (gesso) sob condições de campo. SEÇÃO DE FERTILIDADE DO SOLO E SEÇÃO DE TÉCNICA EXPERIMENTAL E CALCULO, INSTITUTO AGRONÔMICO DO ESTADO DE SÃO PAULO.

EFFECTS OF DIFFERENT SULPHUR SOURCES ON PRODUCTION OF WHEAT

\section{S U M M A R Y}

In a greenhouse trial with wheat growing in pots filled with two red latosols, sulphur was applied as ammonium sulphate, single superphosphate, calcium sulphate (gypsum), and flowers of sulphur.

Highest increases in production were obtained by the use of ammonium sulphate, calcium sulphate (gypsum), and single superphosphate all with comparable effects. 